\title{
Mortality and refusal in the longitudinal 90+ project
}

\author{
Rocío Fernández-Ballesteros a,*, María Dolores Zamarrón a , Juan Díez-Nicolás ${ }^{\mathrm{b}}$, \\ María Dolores Lopez-Bravo ${ }^{c}$, María Ángeles Molina ${ }^{\mathrm{d}}$, Rocío Schettini ${ }^{\mathrm{d}}$ \\ ${ }^{a}$ Department of Psychobiology and Health, Ivan Paulov, 6. Autonomous University of Madrid, 28049 Madrid, Spain \\ ${ }^{\mathrm{b}}$ Department of Sociology: II. Human Ecology and Population, Complutense University, Campus Somosaguas, 28040 Madrid, Spain \\ ${ }^{\mathrm{c}}$ Department of Occupational Therapy, La Salle University Center, La Salle, 1C, 28025 Madrid, Spain \\ d Elderly University Program, Building Posgrado Autonomous University of Madrid, 28049 Madrid, Spain
}

\section{A R T I C L E I N F O}

\section{Article history:}

Received 19 March 2010

Received in revised form 5 September 2010

Accepted 7 September 2010

Available online 12 October 2010

\section{Keywords:}

Very old

Mortality of very old people

Attrition in longitudinal studies

\begin{abstract}
A B S T R A C T
Attrition is one of the most important threats for longitudinal studies on aging mainly due to refusal and mortality. This study deals with those individuals who were assessed in the base line of 90+ project but died, dropped out or were examined in the follow-up. Participants of the 90+ project baseline consist of a sample of 188 older than 90 years, independent individuals (mean age $=92.9 ; 67$ men and 121 women) living in the community $(n=76)$ or in residences $(n=112)$. They were assessed through the European Survey on Aging Protocol (ESAP) by collecting anthropometric, health and life styles, bio-behavioral, psychological and social data. After 6-14 months from the baseline, 55\% individuals were re-assessed, $11 \%$ died and $34 \%$ dropped out for several reasons. Comparisons between the individuals deceased, interviewed and those who dropped out yielded significant differences mainly due to contextual variables. The mortality rate of participants living in residences is three times greater than those of participants living in the community. Trying to determine the differences between these three groups due to bio-psycho-social variables, we found that regular physical activity, mental status, leisure activities, fitness, perceived control and openness assessed at the baseline differentiate our three groups. Finally, $90 \%$ of those individuals who died were identified at the baseline as "non successful agers", while more than a half of those who participated and a third of the non-participants were identified as "successful agers". It can be concluded that among those independent but very old people, mortality is less important than willing to participate and contextual, behavioral and psychological factors are relevant for distinguishing mortality, survival and participation.
\end{abstract}

(c) 2010 Elsevier Ireland Ltd. All rights reserved.

\section{Introduction}

Longitudinal studies have a main threat to the validity of data in terms of attrition. Moreover, high mortality is also another reason for attrition in very old longitudinal studies. Moreover, in those countries where participation in longitudinal and cross-sectional studies is low (such as in some Mediterranean countries) (DíezNicolás, 1996) attrition has another important source, the refusal. Therefore, refusal and mortality are the two threats for longitudinal studies.

Attrition has been defined as losing subjects over the course of a research project. It is considered as one of the most important threat to sample representativeness and generalization of results (Campbell and Stanley, 1966; Vogt, 1993). In aging studies, it is assumed that selective subject attrition produced an underesti-

\footnotetext{
* Corresponding author. Tel.: +34 914975 181; fax: +34 914975215 .

E-mail address: r.fballesteros@uam.es (R. Fernández-Ballesteros).
}

mation of the decline because mortality does not occur at random and individuals drop out. In most of the studies, those individuals who drop out show lower scores both in physical and cognitive performances (Baltes, 1968).

Chatfield et al. (2005) systematically reviewed all large population-based studies of the elderly during the last 35 years that report the differences in individual characteristics between people who remain and people who drop out at follow-up. They showed that two conditions increased attrition: age and cognitive impairment. In summary, people who were very ill or frail had higher dropout rates, and people in worse health were less likely to be followed-up.

There is a broad range of longitudinal studies of aging that test attrition; in these studies, the authors are looking for predictors of participation, mortality and no-participation (due to several causes such as changing residence, rejection to collaborate). Zunzunegui et al. (2001) reviewed the most important results existing in literature about attrition. They found that in longitudinal studies, older individuals with poor 
health, cognitive decline and functional disabilities and unhealthy lifestyles are more likely to be lost. In home surveys, older women were found to drop out more than men, whereas in telephone surveys, no differences between men and women were found. Lower socioeconomic status is associated with lower rates of participation, but others studies report that the high-income population is unwilling to participate by responding to questionnaires. Those living alone have higher probability to drop out. In addition, field study procedures such as interview preparation and interviewer skills play a certain role in participation.

In addition, participation in cross-sectional studies is attributed to contextual factors. For example, Díez-Nicolás (1996) found that in metropolitan areas, among people older than 55 , there is an average of $24.7 \%$ of no participation, but this has a very high range because in some Madrid-areas the non-participation rate is close to $50 \%$.

Although attrition is extensively studied in longitudinal and cross-sectional studies on aging, very few of these studies focus on the very old and even less on those very old living independently. During the last few years, cross-sectional and longitudinal studies focusing on the very old are increasing (Ben-Ezra and Shmotkin, 2006; Schoenhofen et al., 2006; Xie et al., 2008) but very few of them are conducted within the independent very old. The 90+ project tries to examine the bio-psycho-social characteristics of those individuals who remain independent at a very old age. Whether attrition in the independent very old is similar to the other ages or even to the other nonagenarians seems to be important. Finally, although studies in attrition are focusing on the sociodemographic, contextual, health and functional variables, very few of them have searched for bio-psycho-social predictors of attrition.

In summary, as has been emphasized by several authors, mortality and non-participation are not at random. The health, mental status, age, gender, education and SES, living alone or others characteristics such as the level of the answer given at the baseline, and the interviewers seem to be relevant variables that influence attrition. The main objective of the $90+$ project is to describe the very old people living independently, from a multidimensional perspective and, to follow-up on them until they died. This particular report deals with attrition that was examined in the first follow-up of the 90+ study performed after 6-14 months from the baseline. This paper reports several types of dropout (mortality and non-participation) trying to examine several reasons for non-participation by analyzing the influence of sociodemographic factors (age, gender, education, income, living condition, rural-urban context, no-response level in the baseline, the effect of interviewers in participation/non-participation, etc.), as well as the influence of bio-psycho-social factors (cognitive and emotional-motivational functioning, personality and social factors).

\section{Subjects and methods}

\subsection{Participants}

From the last census (INE, 2001) in Spain, 0.55\% of the total population are older than 90 (226,093 inhabitants, 61,383 men, $27 \%$ and 164,710 women, $73 \%$ ). The absolute number of older than 90 with disability impeding independent life in Spain is 118,758 (IMSERSO, 2005) which is approximately 53\% of the older population. In the region of Madrid, at the time of the study there were 55,000 individuals who were older than 90. Therefore, it can be estimated that, in the region of Madrid, there can be approximately 25,000 individuals who are independent persons older than 90 .
The baseline of the $90+$ project, started with a representative sample from the census of older than 90 living in the region of Madrid $(n=1062)$. From this sample only 76 individuals $(7.22 \%)$ could be interviewed $(17.31 \%$ had no telephone, for $15.81 \%$ the phone number provided was incorrect, $30 \%$ did not pick up the phone for at least 5 calls made each day for several days, $11.28 \%$ were dependent or ill, 3.14\% died after the last census, 3.26\% were transferred to a nursing home, $11.67 \%$ refused to participate).

After this very high attrition and by taking into consideration that $11 \%$ of the older than 90 were living in residences, a second procedure was decided for recruiting older than 90 living in residences. At the time of our study, in the region of Madrid 130 older than 90 people were living in 25 residences managed by the region. Six residences did not have older than 90 with our criteria, 4 did not collaborate and 15 residences agreed to collaborate by recruiting 78 subjects with our criteria (60\% of the individuals living in public residences). Finally, we recruited 34 persons who were older than 90 from the private residences who fulfilled our criteria.

Following these two procedures, at the baseline of the 90+ project, 188 individuals older than 90 were the participants, 67 men, 121 women; mean age $92.9 \pm 2.5$ years, ( \pm S.D.), age range: $90-$ 102, 76 living in the community (40\%) and 112 living in residences (60\%). Because our study focused on people living independently, the criteria for inclusion to the sample were as follows: being older than 90 and being independent ("independent life" was assessed by the Barthel Index (BI) (Mahoney and Barthel, 1965) and the Informant Questionnaire On Cognitive decline in the Elderly (IQOCE) (Morales et al., 1995).

Depending on their respective setting, after obtaining informed consent, participants were interviewed and tested at home, or at residence, through the ESAP developed from the EXCELSA-Pilot study (Cross-European Longitudinal Study on Aging-P) (FernándezBallesteros et al., 2004). The ESAP contains 325 variables, by assessing 23 bio-psycho-social functions or measures grouped into nine domains: anthropometry (e.g., height, weight, BMI, etc.); health (e.g., subjective health, number of diagnosed illnesses, sensory functions, need for help, etc.); physical and physiological functions (e.g., blood pressure, balance, speed, vital capacity, strength, subjective fitness), lifestyles (physical activity, nutrition, smoking, drinking, sleep, etc.); cognitive functioning (e.g., cognitive plasticity, working memory, learning, mental status); emotional-motivation functioning (e.g., life satisfaction, well-being, emotional regulation, self-efficacy for aging); personality (extroversion, neuroticism, openness, agreeableness, conscientiousness); social functioning and participation (social and family network and support, helping others, receiving care, leisure activities, social productivity); and sociodemographics (age, gender, marital status, education, income, rural/urban context, etc.). Following several concepts of successful aging, a multidimensional measure of successful aging that was previously developed was used (two or less number of illnesses, 24 or high MMSE score, very or rather satisfied, good or rather good subjective health, Basic ADL conserved (Fernández-Ballesteros et al., in press).

The follow-up was performed between 6 and 14 months from the baseline. From those 188 individuals in the baseline, 104 (55\%) individuals were assessed in the follow-up, 11\% died and 34\% dropped out for several reasons (11.2\% refused to participate, $11.7 \%$ reported to be ill, $2.6 \%$ moved away and $8.4 \%$ were unable to be located, although $2.6 \%$ of them were reported to be alive by their relatives). Table 1 shows the distribution of our 188 participants into "Participant", "Deceased" and "Non-participants" as well as the reason for not participating.

Several statistical analyses were performed. First, analyses about hypothetic factors (interviewers at the baseline, number of items responded to at the baseline, sociodemographic 
Table 1

90+ follow-up: participation, death cases and reasons for non-participation.

\begin{tabular}{lc}
\hline Participants & $n(\%)$ \\
\hline Interviewed & $104(55.0)$ \\
Deceased & $20(11.0)$ \\
Non-participation & $64(34.0)$ \\
Refuse & $21(11.2)$ \\
Reporting illness or cognitive impairment & $22(11.8)$ \\
Moved away & $5(2.6)$ \\
Unable to locate & $16(8.4)$ \\
Total & $188(100.0)$ \\
\hline
\end{tabular}

characteristics) influencing the reasons for not participating were performed. In addition, analyses looking for the differences between the deceased, interviewed and non-interviewed through socioeconomic and contextual variables were performed as well as ANOVAs were made to examine the differences between the three groups by the behavioral and psychosocial variables. Finally, a contingency analysis between deceased/participants/non-participants and active aging/noactive aging at the baseline were performed.

\section{Results}

First, the reasons given for non-participation shown in Table 1 were examined. The non-significant differences between the groups due to interviewers at the baseline $\left(\chi^{2}=21.78, \mathrm{df}=14\right.$, $\mathrm{ns})$ or due to the number of items not answered at the baseline $(F=3.03, \mathrm{df}=2, \mathrm{~ns})$ were found. In addition, no differences were attributed to age $(F=1.48, \mathrm{df}=2, \mathrm{~ns})$, gender $(F=0.40, \mathrm{df}=2, \mathrm{~ns})$, income $(F=0.45, \mathrm{df}=2, \mathrm{~ns})$, education $(F=1.45, \mathrm{df}=2, \mathrm{~ns})$ mental status $(F=1.16$, $\mathrm{df}=2, \mathrm{~ns})$, or number of illnesses reported $(F=0.99, \mathrm{df}=2, \mathrm{~ns})$ were found in the different reasons for dropping out. In summary, non-significant differences were found among the different reasons for not participating given by authors. Therefore, we consider only three categories: deceased, interviewed and non-interviewed.

Table 2 shows the demographic and contextual data in the baseline and in the follow-up of the group for those who were interviewed, not interviewed, or deceased. As we can see in this table, by considering the three categorical conditions (interviewed, not interviewed and deceased) we did not obtain significant differences that can be attributed to the sociodemographic variables such as age, gender, marital status, education and income. Nevertheless, we found that women significantly dropped out more than the men do $\left(\chi^{2}=4.15\right.$, $\mathrm{df}=1, p \leq 0.042$ )

When the contextual variables were examined, significant differences were obtained. Thus, during the follow-up, we had significantly more proportion of deceased individuals among those living in residences than in those living in the community. In addition, we had more individuals participating from those living in the residences than those living in the community and in contrast more individuals living at home refused to participate than those living in the residences $\left(\chi^{2}=16.89 ; \mathrm{df}=1, p<0.0001\right)$.

To identify the relevant bio-psycho-social variables that were assessed (anthropometric, physical and physiological, health and life styles, cognitive and emotional-motivational functioning, personality and psychosocial characteristics) by differentiating those who were deceased, interviewed or dropped out, several ANOVAs were performed. Table 3 shows the parameters that yielded significant differences between the groups. These were, mental status, regular physical activity, leisure, fitness reported, perceived control, and openness to experience.

Finally, since 90+ is a research project searching for independent people in their very old age, a last question remains, to what extent are the deceased and the survivors related to a multidimensional definition of active or successful aging? This

Table 2

Baseline and follow-up data of the study pool, $n$.

\begin{tabular}{|c|c|c|c|c|c|c|}
\hline \multirow[t]{2}{*}{ Sociodemographics } & \multirow[t]{2}{*}{ Baseline } & \multicolumn{3}{|l|}{ Follow-up } & \multirow[t]{2}{*}{ Statistics test } & \multirow[t]{2}{*}{$p<$} \\
\hline & & Participants & Non-participants & Death & & \\
\hline Gender, $n$ & & & & & $\chi^{2}=$ & \\
\hline Men & 67 & 42 & 16 & 9 & 4.94 & n.s. \\
\hline Women & 121 & 62 & 48 & 11 & & \\
\hline Total & 188 & 104 & 64 & 20 & & \\
\hline Age, years & & & & & $F=$ & n.s. \\
\hline Mean & 92.8 & 93.3 & 93.7 & 93.5 & 1.02 & \\
\hline Marital status & & & & & $\chi^{2}=$ & n.s. \\
\hline Single & 26 & 14 & 8 & 4 & 5.20 & \\
\hline Married & 29 & 13 & 14 & 3 & & \\
\hline Separated & 3 & & 1 & 0 & & \\
\hline Divorced & 1 & 1 & 0 & 0 & & \\
\hline Widow & 126 & 71 & 39 & 13 & & \\
\hline Total $n$ & 185 & 99 & 62 & 20 & & \\
\hline Schooling & & & & & $\chi^{2}=$ & n.s. \\
\hline No education & 60 & 34 & 21 & 5 & 11.452 & \\
\hline Primary & 83 & 43 & 28 & 12 & & \\
\hline Secondary & 23 & 11 & 10 & 2 & & \\
\hline High-school & 10 & 5 & 5 & 0 & & \\
\hline College & 12 & 11 & 0 & 1 & & \\
\hline Total $n$ & 188 & 104 & 64 & 20 & & \\
\hline Income & & & & & $\chi^{2}=$ & n.s. \\
\hline Low & 85 & 47 & 27 & 11 & 2.77 & \\
\hline Average & 14 & 7 & 4 & 3 & & \\
\hline High & 12 & 8 & 4 & 0 & & \\
\hline No answer & 77 & & & & & \\
\hline Total $n$ & 188 & 62 & 35 & 14 & & \\
\hline Living conditions & & & & & $\chi^{2}=$ & $\leq 0.001$ \\
\hline Home & 76 & 34 & 38 & 5 & 16.89 & \\
\hline Residence & 112 & 70 & 26 & 15 & & \\
\hline Total $n$ & 188 & 104 & 64 & 20 & & \\
\hline
\end{tabular}

Note: n.s. = not significant. 
Table 3

ANOVA comparisons of the variables yielding significant differences.

\begin{tabular}{lrrll}
\hline Variables & \multicolumn{1}{c}{ Mean \pm S.D. } & $F=$ & $p<$ \\
\hline Mental status & & & & \\
1. Deceased & 19 & $22.47 \pm 4.80$ & 8.309 & 0.001 \\
2. Participant & 104 & $25.60 \pm 3.01$ & & $1-2 ; 1-3$ \\
3. Non-participant & 64 & $24.50 \pm 2.98$ & & \\
Physical activity & & & & \\
1. Deceased & 20 & $1.95 \pm 1.19$ & 9.903 & 0.001 \\
2. Participant & 104 & $3.03 \pm 1.25$ & & $1-2 ; 1-3 ; 2-3$ \\
3. Non-participant & 63 & $2.37 \pm 1.18$ & & \\
Leisure activities & & & & \\
1. Deceased & 16 & $1.30 \pm 0.46$ & 7.272 & 0.001 \\
2. Participant & 80 & $1.76 \pm 0.56$ & & $1-2 ; 2-3$ \\
3. Non-participant & 52 & $1.47 \pm 0.55$ & & \\
Fitness & & & & \\
1. Deceased & 19 & $2.84 \pm 0.75$ & 4.657 & 0.011 \\
2. Participant & 102 & $3.30 \pm 0.67$ & & $1-2$ \\
3. Non-participant & 62 & $3.08 \pm 0.65$ & & \\
Perceived control (1-7 = internal-external) & & \\
1. Deceased & 19 & $4.37 \pm 1.92$ & 4.430 & 0.013 \\
2. Participant & 103 & $3.05 \pm 1.83$ & & $1-2$ \\
3. Non-participant & 62 & $3.29 \pm 2.62$ & & \\
Openness & & & & \\
1. Deceased & 14 & $34.07 \pm 7.30$ & 4.221 & 0.017 \\
2. Participant & 64 & $36.23 \pm 6.48$ & & $2-3$ \\
3. Non-participant & 49 & $32.82 \pm 5.61$ & & \\
\hline
\end{tabular}

Table 4

The occurrence of active aging (yes/no) at the baseline and the other individuals.

\begin{tabular}{lrrrrr}
\hline & \multicolumn{2}{l}{ Active aging } & Total & $\chi^{2}=$ & $p<$ \\
\cline { 2 - 4 } & \multicolumn{1}{c}{ Yes } & No & & & \\
\hline Deceased & 18 & 2 & 20 & 14.32 & 0.001 \\
Dropped out & 41 & 23 & 64 & $(\mathrm{df}=2)$ & \\
Interviewed & 48 & 54 & 102 & & \\
Total & 107 & 79 & 186 & & \\
\hline
\end{tabular}

multidimensional definition has been tested in other studies (Fernández-Ballesteros et al., in press), and it has been adjusted for the very old as: "two or less number of illnesses, 24 or high MMSE score, very or rather satisfied with life, good or rather good subjective health, and basic ADL conserved".

In the baseline, $42.5 \%$ of the individuals were classified as successfully aging. A contingency analysis was performed to assess the proportion of those deceased and the interviewed people who were aging successfully. Table 4 and Fig. 1 show result of this

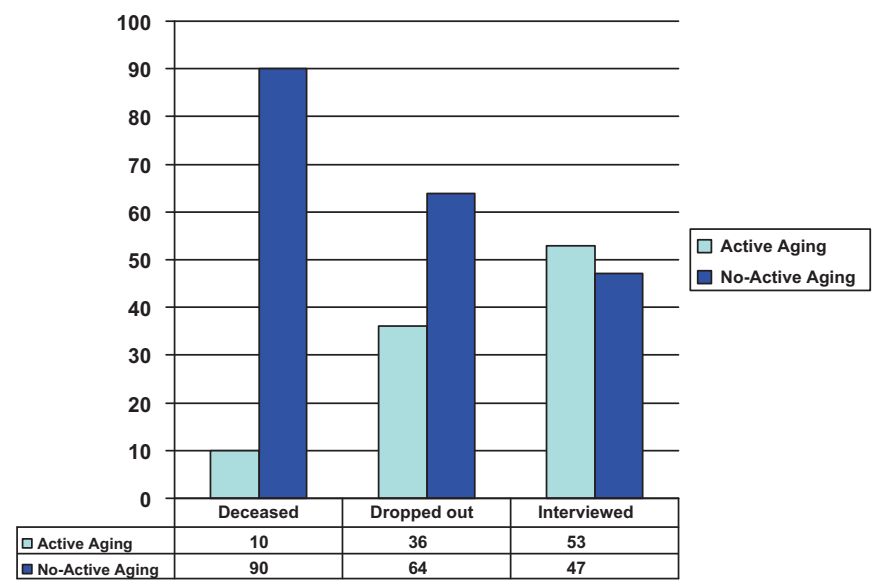

Fig. 1. Percentage of deceased, dropped out, and were interviewed at the follow-up in the $90+$ project who were classified as "Active aging" and "No-Active aging" at the base line. analysis. 90\% ( $n=18)$ of the deceased individuals were classified at the baseline as "not" successfully aging, 69\% $(n=41)$ versus $36 \%$ $(n=23)$ who dropped out were classified as "not" successfully aging, finally, more than a half $(n=54)$ of individual interviewed in the follow-up were classified as successfully aging $\left(\chi^{2}=12.417\right.$, df $=1, p<0.001$ ).

\section{Discussion}

In our 90+ study follow-up, after an average of one year from the baseline, more than a half $(55 \%)$ of our individuals participated in the follow-up. However, attrition was more important due to the participants' dropout (34\%) than to mortality (11\%). As Matthews et al. (2006) pointed out, in longitudinal studies, attrition due to dropout (not to mortality) represents an important threat. It is difficult to make comparisons of our rate of drop out to that of the other studies as most of them were with younger participants and with a longer follow-up period. As emphasized by Nybo et al. (2003), results from the younger elderly cannot be extrapolated to the oldest old. Therefore, let us summarize some comparisons with those longitudinal studies of the very old by taking into consideration that most of them are population studies and therefore are not focused on the independent very old individuals.

The BASE study Baltes et al. (1999) showed that in a sample older than 70, the first dropout in the short initial assessment was $34 \%$, but $51 \%$ in the intake assessment and $73 \%$ in the intensive protocol, respectively. Xie et al. (2008) in a population-based cohort study (in England and Wales) of older than 90, reported interview information from only $45 \%$ of the population. Nybo et al. (2003), from a Danish cohort survey, reported a participation rate at the baseline of $63 \%$. Moreover, other studies with centenarians, such as the Tokyo Centenarian Study reported very low participation about 15\% (Hirose et al., 2004) but the level of participation in other centenarian studies such as the Heidelberg study (Kliegel et al., 2004) reported a 58\% participation. Therefore, our participation rate seems to be in agreement with other studies conducted with very old individuals.

A second relevant issue is to arrive at a profile of those very old individuals who did not respond. As described in Table 1, the nonrespondents were classified as those who refuse to participate, those who reported that they could not participate because of health problems, and those who moved away or who were not located. Contrary to most of the longitudinal studies with young adults, and also, with other studies with the very old, to find differences between the types of non-participation (Chatfield et al., 2005), even after many multivariate analysis (more than 300 variables were tested), we could not arrive at any significant differences that can be attributed to bio-psycho-social conditions between the types of non-respondents. Perhaps, this result can be attributed to the common characteristic of our sample, in other words, to those very old independent individuals who are a very similar.

Regarding mortality as the cause of attrition, in Spain the mortality rate of the older than 89 is $20 \%$ (INE, 2009). Therefore, a mortality of $11 \%$ in our sample is close to half of the rate in the population. We must take into account that the criteria for inclusion in our sample correspond to less than a half of the population older than 90 who are independent. Because mortality is strongly related with age, it is difficult to make comparisons with similar studies (90+ independent older) because we did not find other longitudinal studies on independent very old individuals. Perhaps the closest study was reported by Nybo et al. (2003) referring to the Danish nonagenarian cohort survey in which there was $25.7 \%$ of mortality during the 15 months of follow-up. From the oldest old (older than 90) in England and Wales, Xie et al. (2008) reported that the median of the survival time for those 
reaching their 90th birthday was 3.7 years. In Spain, the expected survival above 90 is 4.56 years. The BASE Study (Baltes et al., 1999), consisting of individuals older than 70 (mean age $=84.9$ ), reports the risk of death within 12 months of $5.5 \%$ versus $13.5 \%$ (13.5\% in verified "father" sample). In summary, the mortality in our sample is smaller than those coming from other nonagenarian studies can be attributed to the selected criteria, therefore, to a lower mortality in the very old group in our study.

The multivariate analyses conducted in order to assess the differential characteristics for each group (deceased, non-participants, and participants) only non-significant results were found regarding the sociodemographic variables commonly found in aging studies on attrition and mortality in aging. Thus, gender is one of the best predictors of mortality in the literature, in our study no significant differences were found among men and women regarding participation and mortality. Nevertheless, this result is supported by other studies (Ben-Ezra and Shmotkin, 2006) on the very old, in which survival is largely similar for both men and women. It is important to emphasize that our results yielded significant differences due to gender between the participants and non-participants: women reject participation more than men. This result is also in accordance with that of Xie et al. (2008), who reported that in England and Wales, women dropped out more than the men. Regarding education and income, these two sociodemographics did not provide significant differences (either using qualitative or quantitative scales, contingency or ANOVA analyses). These results can be attributed to a high percentage of people who did not report his/her income but also, a post hoc explanatory argument can be that, at least in European countries, relative inequalities in mortality decreased with increasing age (Huisman et al., 2004). Regarding our results concerning context, individuals who are living in residences are more likely to die than those living in the community. This result is similar to that of many other studies (Xie et al., 2008).

When multivariate analyses were performed, we found that mental status, regular physical exercise, leisure activities, fitness appraisal, control, and openness to experience differentiate our groups. First, most of the very old studies yielded similar results concerning mental status, in other words cognition is highly associated with mortality (Campbell et al., 1985; Hogan et al., 1999; Nybo et al., 2003) and low cognitive functioning is a good predictor of mortality all through the aging process as well as in the very old. Regular physical activity seems to play an important role in mortality not only in the very olds but also in those who did or did not participate. In our results, regular physical activity is a strong variable that allows us to differentiate between these three groups. Although objective biophysical variables (pick flow, grip strength, tapping, body mass, or balance) did not yield significant results among the types of attrition and/or participation, the subjective appraisal of strength, flexibility, endurance and speed did. Those individuals who were interviewed reported significant better fitness than those who were deceased. In addition, two personality characteristics, openness to experience and internal control, exert a role in attrition. Individuals who were deceased were found to significantly perceive more external control than those who were interviewed. This result is strongly supported by experimental (Rodin and Langer, 1977; Rodin, 1980), crosssectional (Fernández-Ballesteros et al., 2004), and longitudinal studies (Costa and McCrae, 1997). Openness to experience is a personality characteristic showing significant differences between those who were interviewed and those who dropped out. This result is in line with other studies on personality found in literature showing curiosity to be an important variable for participation (Caprara et al., 2007).

Finally, since the criteria for inclusion of our sample make it an exceptional set of independent individuals, it is important to test whether a multidimensional empirical definition of "active aging" (Fernández-Ballesteros et al., in press) at the baseline allows us to differentiate those individuals who deceased, dropped out or participated. That is, even if our sample was selected from the base of the independent nonagenarian, in the baseline, only $42 \%$ of individuals were classified with our multidimensional measure of "successful aging" (low number of illness, high mental status, high life satisfaction, and basic ADL), but, in the follow-up it is possible to differentiate among those individuals who deceased, dropped out or participated. From a theoretical point of view, the hypothesis is that those individuals who deceased must have had a low rate of successful aging than those who were interviewed. In addition, since most of the longitudinal studies assume that those people who did not participate (and are causing attrition) are negatively selective, it can be predicted that they will show a less rate of successful aging. Our formula for assessing successful aging for the very old (few reported illness, high mental status, life satisfaction, high subjective health, basic ADL preserved) allows us to test these two hypotheses. In the follow-up, only $10 \%$ of the deceased individuals were classified in the baseline as "successful agers", 36\% who dropped out were in this situation but more than a half of those who were interviewed were "successfully aging" individuals in the baseline. It could be possible to conclude that although simple indicators are not powerful in accounting for mortality or participation (and attrition) the combination of the individual's functioning can be much more helpful in distinguishing among the individuals, at least in the very old individuals who are living independently. In any case, much more research is required for assessing attrition within the very old.

Some methodological issues should be addressed: at the baseline our representative sample had very high attrition and the proportion of people living in the community is very low (40\%) in comparison with those living in residence. However, the oldest old represent a relatively unknown age group and those who remain independent are even more unknown. From the discovery approach, the $90+$ project tried to learn more about this specific group.

Summarizing, after an average of one year from the baseline, attrition is more in proportion due to drop out than to mortality. We did not find differences among the several reasons for dropping out. Comparisons between those who deceased, were interviewed or not participated showed significant differences due to the context (living in residence or at home). Mental status, regular physical activity, leisure activities, fitness appraisal, internal control that yielded significant differences among those individuals who died and those individuals who were interviewed and openness to the experience distinguished between those who participated and those who dropped out. Finally, a multidimensional measure of successful aging differentiated our three groups.

\section{Conflict of interest statement}

None.

\section{Acknowledgements}

This study has been granted by the National Institute of Aging and Social Services (I+D+I) 200703/06, FGUAM-IMSERSO contract 2008-044511 and the Project SEJ-2006-14438/PSIC.

\section{References}

Baltes, P.B., 1968. Longitudinal and cross-sectional sequences in the study of age and generation effects. Hum. Dev. 11, 145-171.

Baltes, P.B., Mayer, K.U., Helmchen, H., Steinhagen-Thiessen, E., 1999. The Berlin Study (BASE): sample, design, and overview of measures. In: Baltes, P.B., Mayer, 
K.U. (Eds.), The Berlin Aging Study. Aging from 70 to 100. Cambridge University Press, Cambridge, UK, pp. 16-56.

Ben-Ezra, M., Shmotkin, D., 2006. Predictors of mortality in the old-old in Israel: the cross-sectional and longitudinal aging study. J. Am. Geriatr. Soc. 54, 906-911.

Campbell, A.J., Diep, C., Reinken, J., McCosh, L., 1985. Factors predicting mortality in a total population sample of the elderly. J. Epidemiol. Community Health 39, 337-342.

Campbell, D., Stanley, J., 1966. Experimental and Quasi-Experimental Designs for Research. Rand McNally \& Co., Chicago.

Caprara, M.G., Steca, P., Caprara, G.V., 2007. Personality and self-beliefs. In: Fernández-Ballesteros, R. (Ed.), Geropsychology. European Perspectives for an Aging World. Hogrefe and Huber, Göttingen, pp. 103-127.

Chatfield, M.D., Brayne, C.E., Matthews, F.E., 2005. A systematic literature review of attrition between waves in longitudinal studies in the elderly shows a consistent pattern of dropout between differing studies. J. Clin. Epidemiol. 58, 13-19.

Costa, P.T., McCrae, R.R., 1997. Longitudinal stability of adult personality. In: Hogan, R., Johnson, J., Briggs, S. (Eds.), Handbook of Personality Psychology. Academic Press, San Diego, pp. 269-290.

Díez-Nicolás, J., 1996. Los Mayores en la Comunidad de Madrid. Caja de Madrid, Madrid (in Spanish).

Fernández-Ballesteros, R., Zamarrón, M.D., Rudinger, G., Schroots, J.J., Hekkinnen, E., Drusini, A., Paul, C., Charzewska, J., Rosenmayr, L., 2004. Assessing competence: the European Survey on Aging Protocol. Gerontology 50, 330-347.

Fernández-Ballesteros, R., Zamarrón, M.D., López-Bravo, M.D., Molina, M.A., DiezNicolás, J., Montero, P., Schettini, R., in press. Envejecimiento con éxito. Criterios y Predictores. Psicothema, Madrid (in Spanish).

Hirose, N., Arai, Y., Gondoh, Y., Nakazawa, S., Takayama, M., Ebihara, Y., Shimizu, K. Inagaki, H., Masui, Y., Kitagawa, K., Kojima, T., 2004. Tokyo Centenarian Study: aging inflammation hypothesis. Geriatr. Gerontol. Int. 4, S182-S185.

Hogan, D.B., Fung, T.S., Ebly, E.M., 1999. Health, function and survival of a cohort of very old Canadians: results from a second waves of the Canadian Study of Health and Aging. Can. J. Public Health 90, 338-342.

Huisman, M., Kunst, A.E., Andersen, O., Bopp, M., Borgan, J.K., Borrell, C., Costa, G. Deboosere, P., Desplanques, G., Donkin, A., Gadeyne, S., Minder, C., Regidor, E., Spadea, T., Valkonen, T., Mackenbach, J.P., 2004. Socioeconomic inequalities in mortality among elderly people in 11 European populations. J. Epidemiol. Community Health 58, 468-475.
IMSERSO, 2005. Libro blanco de la dependencia. Instituto de Mayores y Servicios Sociales (IMSERSO), Madrid (in Spanish)

INE [Internet], 2001. Censos de población y viviendas 2001, 2001 [updated 2007 July; cited 2009 November 22]. Available: INE [Internet]. Tablas de mortalidad 2005 [updated 2007 October; cited 2009 November 22]. Available from: http:// www.ine.es/jaxi/menu.do?type=pcaxis\&path=\%2Ft20\%2Fp319a\&file=inebase\&L=0 (in Spanish).

Kliegel, M., Moor, C., Rott, C., 2004. Cognitive status and development in the oldest old: a longitudinal analysis from the Heidelberg Centenarian Study. Arch. Gerontol. Geriatr. 39, 143-156.

Mahoney, F.L., Barthel, D.B., 1965. Functional evaluation: the Barthel index. Md State Med. J. 14, 61-65.

Matthews, F.E., Chatfield, M., Brayne, C., 2006. An investigation of whether factors associated with short-term attrition change or persist over ten years: data from the Medical Research Council Cognitive Function and Ageing Study (MRC CFAS). BMC Public Health 6, 185.

Morales, J.M., Gonzalez-Montalvo, J.I., Bermejo, F., Del Ser, T., 1995. The screening of mild dementia with shortened Spanish version of the Informant Questionnaire on Cognitive decline in the Elderly. Alzheimer Dis. Assoc. Disord. 9, 105-111.

Nybo, H., Petersen, H.C., Gaist, D., Jeune, B., Andersen, K., McGue, M., Vaupel, J.W. Christensen, K., 2003. Predictors of mortality in 2,249 nonagenarians: the Danish 1905-Cohort Survey. J. Am. Geriatr. Soc. 51, 1365-1373.

Rodin, J., 1980. Managing the stress of aging. The role of control and coping. In: Levin, S., Ursin, H. (Eds.), Coping and Health. Plenum Press, New York, pp. $171-$ 202.

Rodin, J., Langer, E.J., 1977. Long-term effects of control-relevant intervention with the institutionalized aged. J. Pers. Soc. Psychol. 35, 897-902.

Schoenhofen, E.A., Wyszynski, D.F., Andersen, S., Pennington, J., Young, R., Terry, D.F., Perls, T.T., 2006. Characteristics of 32 supercentenarians. J. Am. Geriatr. Soc. 54, 1237-1240.

Vogt, W.P., 1993. Dictionary of Statistics and Methodology. SAGE Publ., Newbury Park, CA.

Xie, J., Matthews, F.E., Jagger, C., Bond, J., Brayne, C., 2008. The oldest old in England and Wales: a descriptive analysis based on the MRC cognitive function and ageing study. Age Ageing 37, 396-402.

Zunzunegui, M.V., Béland, F., Gutierrez-Cuadra, P., 2001. Loss to follow-up in a longitudinal study on aging in Spain. J. Clin. Epidemiol. 54, 501-510. 